\title{
The effects of experimentally induced stress on false recognition
}

\author{
Jessica D. Payne, Lynn Nadel, John J.B. Allen, Kevin G.F. Thomas, and W. Jake Jacobs \\ University of Arizona, Tucson, AZ, USA
}

\begin{abstract}
The fallibility of memory has become an issue of considerable practical and theoretical importance. Here we studied the impact of experimentally induced stress on the ability of human participants to accurately recognise words presented on a list. We found that stress selectively disrupted participants' ability to distinguish words that were presented for study from critical lure words that were semantically related, but not presented for study. This finding indicates that stress, possibly through its impact on the hippocampus and prefrontal cortex, can potentiate false memories.
\end{abstract}

In recent years memory research has shifted from an emphasis on memory as a matter of accurate reproduction of past events to an acceptance of memory as a reconstructive process that can often go awry (e.g., Neisser \& Winograd, 1988; Roediger, 1996; Schacter, 1995). In a number of practical, as well as experimental, settings, it has become increasingly clear that what an individual recalls or recognises from the past can be influenced by a variety of factors. This renewed emphasis on the fragility of memory has enormous implications, both for theories of how memory is organised, and for all those aspects of life to which memory contributes.

Legal and clinical arenas have been particularly beset by the issue of memory fallibility, as claims have recently been made that memories of early abuse can be accurately recalled years later, after an interval during which the memories were forgotten, or repressed. This so-called "false memory/recovered memory" debate (Conway, 1997; Pezdek \& Banks, 1996) has had a major impact on the lives of many individuals, but as yet scientific analysis has proven incapable of deter- mining whether such "recovered memories" are, or can be, veridical (e.g., Jacobs \& Nadel, 1998).

Recently, links have been drawn between brain structures integral to memory, the hippocampus and prefrontal cortex (PFC), and the stress that must surely accompany the traumatic situations thought to lead to the development of false memories in the real world (e.g., sexual and other types of abuse, stressful eyewitness situations, etc.). These structures have dense concentrations of receptors for glucocorticoids, which are hormones released during stress. There is considerable evidence that stress, or the high levels of glucocorticoids accompanying stress, can impair performance on contextual and episodic memory tasks, which are known to require hippocampal and PFC function (e.g., Henson, Shallice, \& Dolan, 1999; Lupien et al., 1998; Nadel \& Jacobs, 1998). Indeed, even moderate stress levels can impair memory function. A one-time low dose of oral cortisone results in such deficits (de Quervain et al., 2000). These factors suggest that stress could influence the veracity of memory, and the present study was carried out to assess this possibility.

Requests for reprints should be sent to Lynn Nadel, Department of Psychology, University of Arizona, PO Box 210068, Tucson, Arizona 85721-0068, USA. Email: nadel@u.arizona.edu

This study was supported by grants from the Flinn Foundation Biomedical Research Initiative and the McDonnell-Pew Program to the Cognitive Neuroscience Program at the University of Arizona.

We wish to thank Ralf Mertens and Holly Laurance for their help with technical assistance and experimental design, and Betty Glisky, Lee Ryan, and Mary Peterson for their helpful comments on this project. 


\section{METHOD}

\section{Subjects}

A total of 84 undergraduate students from the University of Arizona (44 stressed, 40 non-stressed controls) were tested to determine what influence stress might have on the false recognition of critical lures. Subjects were recruited from lower-division psychology classes and received course credit for their participation. All subjects were treated in accordance with the "Ethical Principles of Psychologists and Code of Conduct" (American Psychological Association, 1992).

\section{Materials and procedure}

We employed a paradigm that has been studied quite extensively in recent years to assess "false" memories in a laboratory setting (Deese, 1959; Roediger \& McDermott, 1995). In brief, subjects are presented with lists of semantically related words (e.g., candy, sour, sugar, bitter, chocolate, cake), and then subsequently given a memory test during which their recognition is assessed for presented words (e.g., candy), non-presented, unrelated "distractor" words (e.g., hat), and semantically related but non-presented "critical lure" words (e.g., sweet). Most experiments employing this Deese-Roediger-McDermott (DRM) paradigm have yielded a moderately high rate of false recognition of non-presented critical lure words (Roediger, McDermott, \& Robinson, 1998). We tentatively hypothesised that learning lists while under stress might increase false recognition of critical lures beyond what is typically found in standard (non-stressful) DRM experiments.

Stress was induced using the 'Trier Social Stress Test' (Kirschbaum, Pirke, \& Hellhammer, 1993), a procedure that reliably elicits moderate psychological stress in laboratory settings. Subjects delivered a speech in front of a one-way mirror. They were told that three trained investigators were located behind this mirror. The speech was made standing in front of a microphone, in the presence of two tripod-mounted 1000 watt halogen stage lights, and subjects believed they were being audio and video recorded for later analysis. Subjects were given 10 minutes to prepare their speeches, after which time their notes were abruptly taken and they were told they would have to give the speech extemporaneously. The speech lasted for a full 5 minutes and was followed by a moderately difficult 5-minute subtraction task (subjects serially subtracted 13 from the number 1022 aloud and without stopping).

After receiving the stress manipulation, subjects listened to 20 of the word lists developed by Deese (1959) and modified by Roediger and McDermott (1995). Following a practice trial to familiarise subjects with the procedure, subjects were told to listen carefully to the upcoming wordlists, and to remember as many words as possible for subsequent recognition tests. All 20 lists contained 15 of the most common associates to a nonpresented critical lure word (Roediger \& McDermott, 1995). After the presentation of each list, subjects were given a four-word recognition test, during which they indicated whether they had, or had not, heard each word on the previously presented list. Recognition words were presented via computer, where each word remained the screen for 2 seconds. One of these recognition words was actually presented in the list (presented word), while the other three words were not; of these, two words were unrelated distractor words, and the other was the theme word to which all presented words are semantically related (critical lure word). Responses were made by pressing one of four keys; "K" corresponded to "Sure I heard the word", "J" to "Somewhat sure I heard the word", "D" to "Sure I didn't hear the word", and "F" to "Somewhat sure I didn't hear the word". Responding via computer allowed measurement of reaction time data, which were collected for each response type. All data were then collapsed for analysis into two response categories, "sure or somewhat sure I heard the word" or "sure or somewhat sure I didn't hear the word".

\section{RESULTS}

As Table 1 shows, stress did not affect the accuracy of memory for presented words. This observation is supported by a one-way analysis of variance (ANOVA) demonstrating no significant difference between the stress group's hit rate $(M=$ $0.82)$ and the hit rate of non-stressed controls $(M=$ $0.78), F(1,83)=1.91, p>.1$. In contrast, stress did increase rates of false recognition. Subjects in the stress group erroneously recognised a significantly higher proportion of critical lures $(M=0.77)$ than subjects in the no-stress group $(M=0.61)$, [ANOVA, $F(1,83)=6.0, p<.01]$. The effects of stress were specific to false recognition, as subjects 
TABLE 1

Mean proportion of "yes" responses to presented words, unrelated distractors, and critical lures for stressed and nonstressed subjects

\begin{tabular}{lcc}
\hline \multirow{2}{*}{ Word type } & \multicolumn{2}{c}{ Stress condition } \\
Stress & No-stress \\
\hline Presented "old" words & .82 & $.78(\mathrm{~ns})$ \\
Unrelated distractors & .04 & $.03(\mathrm{~ns})$ \\
Critical lures & .77 & $.61^{*}$ \\
\hline
\end{tabular}

* Indicates a significant difference between stress and nostress groups on "yes" responses to critical lures $(p<.01)$. "ns" indicates a non-significant difference between stress and nostress subjects on "yes" responses to presented items and unrelated distractors $(\mathrm{p}>.1)$.

made few incorrect responses (false alarms) to unrelated distractor words $(M \mathrm{~s}=0.04$ and 0.03 for stressed and non-stressed subjects, respectively, $p>.1)$.

As in previous DRM experiments (Roediger et al., 1998), non-stressed subjects falsely recognised a substantial proportion of critical lures (61\%). Stressed subjects, however, made significantly more false memory errors than did non-stressed controls. This higher rate of false alarms to critical lures appears to be the only way in which responses of the stress and no-stress groups dif- fered; both groups had similar hit rates and similar false alarm rates to unrelated distractors. These results indicate that the impact of stress on false memory cannot be explained as a general impairment of memory performance, but rather reflects a specific impact on aspects of retrieval that permit accurate reconstruction of prior experience. To confirm this interpretation, a repeated-measures ANOVA was performed, with a three-level "wordtype" variable (presented word, unrelated distractor word, or critical lure word) as the repeated measure. As expected, this analysis revealed a clear main effect of stress condition, and a significant stress by wordtype interaction, $F(2,83)=3.17, p<.05$ (see Figure 1$)$.

To determine whether presented words and critical lures were in any way distinguishable, group differences were examined between the proportion of "yes" responses made to presented words and critical lures for each experimental group. A significant difference emerged for the no-stress group. Their correct identification of presented words $(78 \%)$ exceeded their false identification of critical lures $(61 \%), p<.01$. This difference indicates that despite a moderately high proportion of false recognition, non-stressed subjects possessed some residual ability to distinguish critical lures from presented items. For the

\section{Stress $\mathrm{x}$ Wordtype Interaction}

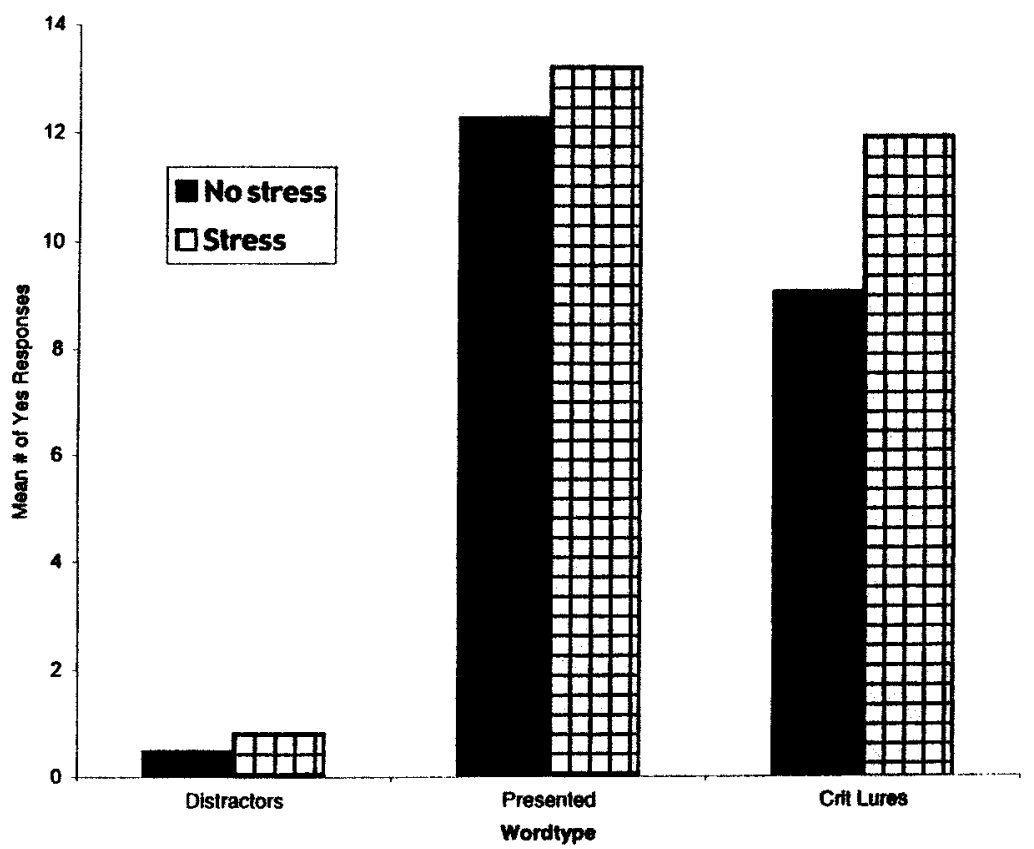

Figure 1. Mean number of "yes" responses to unrelated distractors, presented words, and critical lures. 
stress group, however, this was not the case; the correct identification of presented words $(81 \%)$ did not differ from the false identification of critical lures $(77 \%),(p>.10)$. It appears that stressed subjects were entirely unable to distinguish actually presented words from non-presented critical lures.

We considered the possibility that if stressed subjects possessed any residual ability to differentiate between critical lures and presented items, it might be reflected in their reaction time data. If such an ability existed, subjects might show some sign of hesitation when responding incorrectly to critical lures. However, this pattern of results emerged only in the no-stress control group. A repeated-measures ANOVA revealed that when responding affirmatively (i.e., when making a "yes" response to indicate they had heard a word), non-stressed subjects responded significantly faster to correctly recognised presented items $(M=1081.68 \mathrm{~ms})$ than to falsely recognised critical lures $(M=1172.02 \mathrm{~ms}), F(1,39)=5.47, p<$ .05. No such distinction was observed in the stressed subjects, who had similar reaction times to presented items and critical lures $(M \mathrm{~s}=1057.73$ $\mathrm{ms}$ and $1076.30 \mathrm{~ms}$, respectively, $p>.1)$. Thus, not only did stressed subjects make "yes" responses to presented items and critical lures equally often (see earlier), they also responded to these two types of words equally quickly.

The fact that control subjects hesitated when making false recognition errors to critical lures suggests that on some level veridical and false memories are represented differently. The absence of any sign of such differentiation in the stressed subjects indicates that stress makes it difficult, if not impossible, to distinguish between presented words, and non-presented words that are merely related to the gist of a list.

\section{DISCUSSION}

Our results clearly suggest that stress increases at least one type of false memory-the false recognition of semantically related words that were never presented for study. Why is this so? In order to answer this question, one must first consider why there is such a prominent rate of false recognition in non-stressed subjects (Roediger et al., 1998). In a recognition experiment of the sort conducted here, correct performance is not a matter of remembering whether or not one has ever seen the words on the recognition test; most, if not all, of these words are quite common and are undoubtedly familiar to the subjects. Rather, correct performance requires remembering that one saw particular words in the specific experimental context.

Current conceptual treatments of false recognition in the DRM paradigm emphasise two possible ways in which contextual remembering might be impeded by the presentation of numerous semantic associates. First, exposure to a word may cause the activation of semantically related words (e.g., Underwood, 1965). Presentation of an entire list of related words more or less guarantees that the critical lure will undergo considerable activation, and this activation leads to the sense that the word has been presented when the recognition test is performed. Mere activation of a non-presented word may result in a profound sense of familiarity, or the feeling that one actually encountered the word on the list. This sense of familiarity leaves subjects with the difficult task of deciding whether they really heard the word on the list, or merely thought of it as they were listening to the list. This difficulty is commonly described as a "source-monitoring" problem (see Johnson, Hashtroudi, \& Lindsay, 1993). There is some disagreement as to whether this activation is merely implicit, or whether the subject explicitly thinks of the related word at the time (McDermott, 1997; McKone \& Murphy, 2000; Seamon et al., 2000). Second, subjects may remember the gist of what they have experienced (i.e., the "theme" of the word-list), rather than the specific details (i.e., the individual words). This reliance on gist leads naturally to false recognition of semantically related, but non-presented, words (Brainerd \& Reyna, 1998).

Both of the foregoing theoretical explanations for false recognition (spreading activation and gist processing) help to clarify why unstressed subjects incorrectly recognise such a high proportion of non-presented lure words. In spite of this high rate of false recognition, it is important to note that unstressed subjects do retain some ability to distinguish between presented items and critical lures; in the present experiment, for instance, critical lures were correctly identified as "not heard" approximately $40 \%$ of the time. Stressed subjects, however, appeared to lose this ability to distinguish between "true" and "false" memories in the DRM paradigm. We suspect that this reflects the role of the hippocampal and PFC systems in contextual remembering, and the modulation of these systems by stress. 
As noted, one way to overcome the misleading effects of activation or gist is to encode presented words into a contextual representation. There is general agreement that the hippocampal system is important in representing context (Nadel \& Willner, 1980), perhaps by binding together elements of the contextual situation and events that make up a given episode (Nadel, 1991). Evidence that PFC plays a role in such binding exists as well (e.g., Mitchell, Johnson, Raye, \& D'Esposito, 2000), possibly via modulating effects on hippocampal processing or a more direct role in sourcemonitoring (Rugg, Fletcher, Chua, \& Dolan, 1999). Participation in this experiment constitutes an episode for our subjects, one that consisted of multiple events and is uniquely defined by the context in which those events occur. Events in the experimental scenario include: where one was (in a psychology laboratory), the purpose one had in being there (to participate in an experiment), what one was instructed to do (to listen to lists of words), what one's goal was (to indicate whether or not certain recognition words had appeared on the lists), the words actually presented in the lists, the order in which these words were presented, what the words sounded like, and so on. The hippocampus is presumed to be essential for representing this contextual information and for keeping track of, by binding together, the unique elements of a given memory trace that make it a distinct episode (Nadel, 1994). By drawing on these contextual representations, subjects may be better able to distinguish words that were presented in the experiment from other semantically related but non-presented words. The residual ability of unstressed subjects to distinguish between presented words and non-presented lures might reflect this capacity.

Through its impact on the hippocampus and PFC, stress may impair an individual's ability to encode the contextually specific information that defines words as belonging to a particular experimental setting. This impairment, in turn, could make it impossible to distinguish between words actually presented in this context and semantically related non-presented words. This follows from both the spreading activation and gist processing accounts of false recognition described earlier.

In the spreading activation account, the ability to encode contextually specific, distinctive information generally helps subjects distinguish between presented words and non-presented words that were merely activated. For instance, contextual processing of presented words might lead to an emphasis on item-specific information, such as where in a list the word appeared, what it sounded like, etc. Words that were merely activated would lack this kind of contextual detail (see Schacter et al., 1996). In this view, stress disrupts the contextual representation that would form under normal conditions, thereby making it difficult, if not impossible, to distinguish between actually presented and merely activated words.

In the gist processing account, contextually specific, detailed information about words should help subjects overcome reliance on gistbased representations. In stressful conditions, both context-based and gist-based representations are operative; context-based representations emphasise what is unique about a specific experience, whereas gist-based representations emphasise the generic aspects of experience that cut across specific experiences. Under normal conditions both kinds of representations are available, but stress impairs the context-based system, thus allowing gist-based representations to dominate performance. Within both the activation and gist processing accounts of false recognition then, contextual information could play an important role in minimising confusion between presented words and non-presented lures. When stress disrupts hippocampal and/or PFC processing, false recognition increases dramatically. Whether this disruptive role of stress targets the hippocampus, and the contextual representations dependent on this brain structure, the PFC and accurate memory for "source", or the binding process dependent on both, remains to be determined. Whatever the precise localisation of stress effects on false recognition, this study has demonstrated that moderate psychological stress renders subjects unable to distinguish between "true" and "false" memories in the DRM paradigm.

The results of this experiment have clear implications for theories of false memory, and for the false memory debate itself. Although the paradigm used here is admittedly artificial and may not generalise readily to real-world scenarios, it is widely used in the laboratory to study false memory, and provides an important first step in demonstrating that stress can potentiate false memories. 


\section{REFERENCES}

American Psychological Association. (1992). Ethical principles of psychologists and code of conduct. American Psychologist, 47, 1597-1611.

Brainerd, C.J., \& Reyna, V.F. (1998). When things that were never experienced are easier to "remember" than things that were. Psychological Science, 9, 484489.

Conway, M.A. (Ed.). (1997). Recovered memories and false memories. Oxford: Oxford University Press.

Deese, J. (1959). On the prediction of occurrence of particular verbal intrusions in immediate recall. Journal of Experimental Psychology, 58, 17-22.

de Quervain, D.J.F., Roozendaal, B., Nitsch, R.M., McGaugh, J.L., \& Hock, C. (2000). Acute cortisone administration impairs retrieval of long-term declarative memory in humans. Nature Neuroscience, 3, 313-314.

Henson, R.N.A., Shallice, T., \& Dolan, R.J. (1999). Right prefrontal cortex and episodic memory retrieval: A function MRI test of the monitoring hypothesis. Brain, 122, 1367-1381.

Jacobs, W.J., \& Nadel, L. (1998). Neurobiology of reconstructed memory. Psychology, Public Policy and Law, 4, 1110.

Johnson, M.K., Hashtroudi, S., \& Lindsay, D.S. (1993). Source monitoring. Psychological Bulletin, 114, 3-28.

Kirschbaum, C., Pirke, K.-M., \& Hellhammer, D.H. (1993). The "Trier Social Stress Test": A tool for investigating psychobiological stress responses in a laboratory setting. Neuropsychobiology, 28, 76-81.

Lupien, S.J., de Leon, M., De Santi, S., Convit, A., Tarshish, C., Nair, N.P.V., Thakur, M., McDwen, B.S., Hauger, R.L., \& Meaney, M.J. (1998). Cortisol levels during human aging predict hippocampal atrophy and memory deficits. Nature Neuroscience, 1, 69-73.

McDermott, K.B. (1997). Priming on perceptual implicit memory tests can be achieved through presentation of associates. Psychonomic Bulletin \& Review, 4, 582-586.

McKone, E., \& Murphy, B. (2000). Implicit false memory: Effects of modality and multiple study presentations on long-lived semantic priming. Journal of Memory \& Language, 43, 89-109.

Mitchell, K.J., Johnson, M.K., Raye, C.L., \& D'Esposito, M. (2000). fMRI evidence of age-related hippocampal dysfunction in feature binding in working memory. Cognitive Brain Research [On-line serial], 1. Available FTP: www.elseview.com/locate/bres
Nadel, L. (1991). The hippocampus and space revisited. Hippocampus, 1, 221-229.

Nadel, L. (1994). Multiple memory systems: What and why. An update. In D.L. Schacter \& E. Tulving (Eds.), Memory systems 1994 (pp. 39-63). Cambridge, MA: MIT Press.

Nadel, L., \& Jacobs, W.J. (1998). Traumatic memory is special. Current Directions in Psychological Science, 7, 154-157.

Nadel, L., \& Willner. (1980). Context and conditioning: A place for space. Physiological Psychology, 8, 218228.

Neisser, U., \& Winograd, E. (Eds.). (1988). Remembering reconsidered: Ecological and traditional approaches to the study of memory. Cambridge: Cambridge University Press.

Pezdek, K., Banks, W.P. (Eds.). (1996). The recovered memory/false memory debate. San Diego, CA: Academic Press.

Roediger, H.L., (1996). Memory illusions. Journal of Memory and Language, 35, 76-100.

Roediger, H.L., \& McDermott, K. (1995). Creating false memories: Remembering words not presented on lists. Journal of Experimental Psychology: Learning, Memory, \& Cognition, 21, 803-814.

Roediger, H.L., McDermott, K., \& Robinson, K.J. (1998). The role of associative processes in creating false memories. In M.A. Conway, S.E. Gathercole, C. Cornoldi (Eds.), Theories of memory II (pp. 187245). Hove, UK: Psychology Press.

Rugg, M.D., Fletcher, P.C., Chua, P.M.-L., \& Dolan, R.J. (1999). The role of the prefrontal cortex in recognition memory and memory for source: An fMRI study. NeuroImage, 10, 520-529.

Schacter, D.L. (1995). Memory distortion: How minds, brains and societies reconstruct the past. Cambridge, MA: Harvard University Press.

Schacter, D.L., Reiman, E., Curran, T., Yun, L.S., Bandy, D., McDermott, K.B. \& Roediger, H.L. (1996). Neuroanatomical correlates of veridical and illusory recognition memory: Evidence from positron emission tomography. Neuron, 17, 267-274.

Seamon, J.G., Luo, C.R., Schlegel, S.E., Greene, S.E., \& Goldenberg, A.B. (2000). False memory for categorized pictures and words: The category associates procedure for studying memory errors in children and adults. Journal of Memory \& Language, 42, 120146.

Underwood, B.J. (1965). False recognition produced by implicit verbal responses. Journal of Experimental Psychology, 70, 122-129. 